\title{
Caracterização de Requeijão Marajoara e Minas Frescal produzidos com leite de búfalas no Estado do Pará, Brasil
}

\author{
Characterization Requeijão Marajoara and Minas Frescal produced with buffalo milk in \\ Pará State, Brazil
}

\author{
Ruth Helena Falesi Palha de Moraes Bittencourt ${ }^{\mathrm{I}^{*}}$ Marco Antonio Sloboda Cortez ${ }^{\mathrm{II}}$ \\ Eliane Teixeira Mársico ${ }^{\text {II }}$ Rosa Maria Souza Santa Rosa ${ }^{\text {III }}$ Cristina Maria Araújo Dib Taxi ${ }^{\text {II }}$ \\ Cristian Faturi ${ }^{I}$ Pedro Ancelmo Nunes Ermita ${ }^{I}$
}

\section{RESUMO}

Trinta amostras de queijo tipo Requeijão Marajoara e trinta de Minas Frescal, elaborados com leite bubalino foram analisadas, visando a caracterizar os teores dos principais componentes e características físico-químicas. Os queijos foram obtidos de estabelecimentos industriais localizados nos municípios de Salvaterra, Ilha de Marajó e Moju, nordeste do Estado do Pará. Os dados obtidos foram analisados por meio de Análise Descritiva, utilizando o pacote estatístico $S A S^{\circledR}$. Para o Requeijão Marajoara, os resultados médios foram: $p H$ de 5,15 $( \pm 0,13)$; acidez $0,62 \%( \pm 0,08)$; umidade $43 \%( \pm 1,64)$; gordura $31,57 \%$ $( \pm 3,13)$; gordura no extrato seco (GES) 55,84\% ( $\pm 4,38)$; proteína $34,59 \%( \pm 1,68)$; e cinzas $2,45 \%( \pm 0,47)$. Para o Minas Frescal, o $\mathrm{pH}$ foi de $6,26( \pm 0,69)$, acidez $0,15 \%( \pm 0,14)$, umidade $60,99 \%$ $( \pm 2,58)$, gordura $25,09 \%( \pm 1,68)$, GES $62,95 \%( \pm 4,38)$, proteína $11,06 \%( \pm 1,65)$ e as cinzas $2,09 \%( \pm 0,32)$. A variação entre os macronutrientes e as características físico-químicas nas amostras estudadas revelou falta de padronização na tecnologia empregada no processamento, o que pode estar relacionada à inexistência de legislações específicas para a elaboração desses derivados com leite bubalino. Conclui-se que é fundamental o estabelecimento de critérios de processamento e requisitos legais, objetivando a obtenção de produtos padronizados, com consequente agregação de valor.

Palavras-chave: leite de búfala, Minas Frescal, análises físicoquímicas, Requeijão Marajoara.

\section{ABSTRACT}

Thirty samples of Requeijão Marajoara cheese and thirty samples of Minas Frescal cheese, made both with buffalo milk, were analyzed to determine main components levels and physicochemical characteristics. The cheeses were obtained from industrial establishments located in the municipalities of Salvaterra, Marajó Island, and Moju, northeastern of Pará State.
The data were statistically analyzed by Descritive Analyses, using the SAS ${ }^{\circledR}$ system. For the Requeijão Marajoara, the average results obtained were: $p H 5.15$ ( \pm 0.13$)$; acidity $0.62 \%( \pm 0,08)$; moisture $43 \%( \pm 1.64)$; fat $31.57 \%( \pm 3.13)$; fat on dry extract (FDE) $55.84 \%$ ( \pm 4.38$)$; protein $34.59 \%( \pm 1.68)$; and ash $2.45 \%$ $( \pm 0.47)$. For the Minas Frescal $p H 6.26( \pm 0.69)$; acidity $0.15 \%$ ( \pm 0.14$)$; moisture $60.99 \%$ ( \pm 2.58$)$; fat $25.09 \%$ ( \pm 1.68$)$; fat on dry extract $(F D E) 62.95 \%( \pm 4.38)$; protein $11.06 \%$ ( \pm 1.65$)$; and ash $2.09 \%( \pm 0.32)$. The variation between macronutrients and physicochemical characteristics revealed standardization lack in the technology used in the processing, what can be related to the inexistence of specific legislations for the elaboration of these flowed from buffalo milk. It's crucial the establishment of criteria for processing and legal requirements, aiming to obtain standardized products, with consequent aggregation of values.

Key words: buffalo milk, Minas Frescal, physicochemical analysis, Requeijão Marajoara.

\section{INTRODUÇÃO}

O interesse pela diversificação do uso do leite de búfala na elaboração de produtos derivados vem aumentando em virtude do elevado rendimento do processamento industrial, visto que o leite de búfala apresenta composição química superior em qualidade, em relação ao leite da vaca, em $43,81 \%$ nos sólidos totais, $43,60 \%$ na gordura, $17,10 \%$ no extrato seco desengordurado, $41,54 \%$ na proteína (caseína), 2,4\% na lactose, $15,30 \%$ no resíduo mineral fixo, $42,10 \%$ no cálcio e $42,86 \%$ no fósforo (HÜHN et al., 1982). Entretanto, apesar do valor nutritivo e

\footnotetext{
Instituto da Saúde e Produção Animal (ISPA), Universidade Federal Rural da Amazônia (UFRA), campus Belém, Av. Presidente Tancredo Neves, 2501, Terra Firme, 66077-901, Belém, PA, Brasil. E-mail: ruth.bittencourt@ufra.edu.br. *Autor para correspondência.

IIDepartamento de Tecnologia de Alimentos, Faculdade de Veterinária, Universidade Federal Fluminense (UFF), Niterói, RJ, Brasil

IIIInstituto Sócioambiental e dos Recursos Hídricos (ISARH), UFRA, Belém, PA, Brasil.
} 
rendimento industrial desse leite superarem o leite de vaca, pouco se tem feito para regulamentação de normas de padrão de identidade e qualidade desse leite (AMARAL et al., 2005).

Entre os queijos tradicionalmente produzidos no Brasil utilizando o leite de búfalas, destacam-se o Mozzarella, o Marajoara, o CPATU branco (produzido pela Embrapa), o Provolone, a Ricota, o Mascarpone e o Minas Frescal; requerendo, cada tipo de queijo, uma técnica de produção específica (VERRUMA-BERNARDI et al., 2000; CUNHA NETO, 2003; SILVA \& OLIVEIRA, 2003; MORAES et al., 2006).

O queijo Minas Frescal é um queijo fresco, semigordo, de muito alta umidade, obtido por coagulação enzimática do leite com coalho e/ou outras enzimas coagulantes apropriadas, complementada ou não com ação de bactérias lácticas específicas (BRASIL, 1997a; 2004).

O Requeijão Marajoara é um produto obtido pela fusão de mistura de creme, gordura ou nata, com massa de coalhada (coagulação espontânea do leite), dessorada e lavada, sendo classificado como queijo de massa cozida, não maturado e não prensado, de textura macia, aroma agradável, levemente ácido e salgado e elaborado semelhante ao requeijão tradicional (HÜHN et al., 1986; LOURENÇO, 1999; VIEIRA et al., 2005).

$\mathrm{Na}$ região Norte, a industrialização do leite de búfala tem representatividade econômica e social. No Estado do Pará, o interesse na utilização desse leite na produção de queijos, dentre os quais os tipos Requeijão Marajoara e Minas Frescal vem aumentando consideravelmente.

Apesar desse crescimento, são escassas as informações referentes à tecnologia utilizada no processamento desses queijos. O obstáculo para a padronização desses queijos é a inexistência de padronização das características físico-químicas.

O objetivo do presente estudo foi avaliar as características físicas e químicas dos queijos tipo Requeijão Marajoara e Minas Frescal, produzidos com leite de búfalas, em estabelecimentos industriais localizados nos municípios de Salvaterra, Ilha de Marajó e Moju, no Estado do Pará, contribuindo com informações relevantes sobre a qualidade nutricional e consequente agregação de valor a esses produtos.

\section{MATERIAL E MÉTODOS}

Foram obtidas 30 amostras de Requeijão Marajoara tipo creme e 30 de queijo Minas Frescal, produzidos com leite de búfalas da raça Murrah, em estabelecimentos industriais localizados, respectivamente, nos municípios de Salvaterra (latitude $00^{\circ} 45^{\prime} \mathrm{S}$ e longitude $48^{\circ} 31^{\prime} \mathrm{O}$ ) na Ilha de Marajó, e Moju (latitude de $01^{\circ} 53$ 'S e longitude de $\left.48^{\circ} 46^{\circ} \mathrm{O}\right)$ na região nordeste do Estado do Pará, durante o período de janeiro a outubro de 2010.

Três amostras de cada queijo foram coletadas mensalmente e mantidas congeladas a $18^{\circ} \mathrm{C}$ até o momento das análises físico-químicas, realizadas no Centro de Tecnologia Agropecuária da Universidade Federal Rural da Amazônia.

As análises físico-químicas consistiram de acidez titulável (em \% de ácido lático), $\mathrm{pH}$ (método potenciométrico), umidade (secagem em estufa), cinzas totais (incineração em mufla), proteínas (método de Kjeldahl) e gordura (método butirométrico de Gerber para queijo), conforme metodologias descritas na Instrução Normativa no 68, de 12 de dezembro de 2006 (BRASIL, 2006). Todas as análises foram feitas em triplicata.

Gordura no extrato seco (GES) foi calculada através da fórmula: $\%$ GES $=(\%$ gordura $\div$ \% extrato seco) x 100. Os parâmetros da composição físico-química dos queijos foram analisados por meio de Análise Descritiva, utilizando o pacote estatístico SAS $^{\circledR}$ (SAS, 1997).

\section{RESULTADOS E DISCUSSÃO}

Os resultados obtidos nas análises físicoquímicas no queijo tipo Requeijão Marajoara encontram-se registrados na tabela 1 . O valor médio de $\mathrm{pH}$ encontrado no Requeijão Marajoara tipo creme foi de 5,15, sendo menor que os determinados por LOURENÇO (1999) no mesmo tipo de requeijão também produzido com leite bubalino, que encontrou valores em torno de 5,26 a 5,41.

A acidez titulável de $0,62 \%$ de ácido lático foi maior do que as observadas por SOUSA et al. (2002) (0,16 a 0,20\% de ácido lático) e por FIGUEIREDO (2006) (0,18\%), ao investigarem o mesmo tipo de requeijão elaborado com leite bubalino.

Segundo BENDELAK (2005), o requeijão é um queijo que durante o processamento é submetido a um processo de fermentação da massa, muitas vezes, natural, em virtude da ação das bactérias lácteas próprias do leite, o que corrobora os valores de acidez elevados e baixo $\mathrm{pH}$ encontrados neste experimento.

Relativo ao teor de umidade de 43,01\%, resultados semelhantes, nesse derivado lácteo bubalino, foram relatados por SOUSA et al. (2002) e BENDELAK (2004), que observaram a umidade 
Tabela 1 - Composição físico-química do queijo tipo Requeijão Marajoara elaborado a partir do leite de búfalas no município de Salvaterra, Pará. Belém, 2011.

\begin{tabular}{|c|c|c|c|c|}
\hline \multirow{2}{*}{ Parâmetros Avaliados } & \multirow[b]{2}{*}{ Média $\pm \sigma$} & \multirow[b]{2}{*}{ Máximo } & \multirow[b]{2}{*}{ Mínimo } & \multirow{2}{*}{$\mathrm{CV}(\%)$} \\
\hline & & & & \\
\hline Gordura no Extrato Seco (\%) & $55,84 \pm 4,38$ & 62,15 & 46,62 & 7,84 \\
\hline Umidade (\%) & $43,01 \pm 1,64$ & 46,09 & 39,85 & 3,81 \\
\hline Gordura (\%) & $31,57 \pm 3,13$ & 35,83 & 23,25 & 9,91 \\
\hline Proteína (\%) & $19,51 \pm 1,68$ & 23,18 & 15,39 & 8,61 \\
\hline Cinzas $(\%)$ & $2,47 \pm 0,47$ & 3,5 & 1,57 & 19,00 \\
\hline $\mathrm{pH}$ & $5,15 \pm 0,13$ & 5,41 & 4,90 & 2,52 \\
\hline Acidez Titulável (\% de ácido lático) & $0,62 \pm 0,08$ & 0,74 & 0,41 & 12,90 \\
\hline
\end{tabular}

CV - Coeficiente de variação.

variando, respectivamente, entre 39,78 a $47,89 \%$ e 40,48 a 43,10\%, enquanto que LOURENÇO, SIMÃO NETO \& LOURENÇO JÚNIOR (2002) descreveram teor mais elevado, de 50\%, e LOURENÇO (1999) e FIGUEIREDO (2006) percentuais menores, respectivamente, 38,15 a $42,11 \%$ e $37,77 \%$, o que demonstra a falta de padronização desse produto.

O teor médio de gordura de $31,57 \%$ foi similar aos 28,05 a $38,14 \%$ encontrados por SOUSA et al. (2002), no entanto, menor do que os observados por GOUVEIA \& DIAS (2004) (34,86 a 37,18\%) e por FIGUEIREDO (2006) $(34,40 \%)$ e maior do que os obtidos por LOURENÇO (1999) (29,60 a 30,16\%) e por LOURENÇO, SIMÃO NETO \& LOURENÇO JÚNIOR (2002) (22\%).

Para a concentração de Gordura no Extrato Seco (GES), o valor encontrado de 55,84\% no Requeijão Marajoara assemelhou-se aos resultados de 51,27 a $64,46 \%$ obtidos por SOUSA et al. (2002) e de 54,78 a $55,27 \%$ por FIGUEIREDO (2006), no mesmo tipo de requeijão também elaborados a partir do leite bubalino.

Ressalta-se que, relativo à GES, os resultados obtidos se mostraram acima do estabelecido na Portaria no 359 para o requeijão de corte produzido com leite de vaca. No entanto, esses teores estão de acordo com o preconizado para o requeijão de manteiga produzido com leite bovino (BRASIL, 1997b), considerando o recomendado na Portaria $n^{\circ} 146$ (BRASIL, 1996), que estabelece os teores de gordura no extrato seco para queijos, definindo o requeijão como queijo gordo.

$\mathrm{O}$ teor de gordura encontrado neste experimento, com reflexos na gordura no extrato seco, pode ser atribuído a não padronização da quantidade de creme adicionado ao Requeijão Marajoara durante o processamento, conforme referiram LOURENÇO (1999) e TORO \& SOUSA (2002).
A concentração de proteína, 19,51\%, encontrou-se dentro das variações relatadas por LOURENÇO (1999), entre 18,9 e $24,6 \%$, por SOUSA et al. (2002), entre 15,61 e $22,13 \%$, por GOUVEIA \& DIAS (2004), de 19,10 a 20,73\% e por FIGUEIREDO (2006), 19,25\%, no mesmo tipo de requeijão, entretanto, inferior ao citado por TORO \& SOUSA (2002), que referiram valor de $21,52 \%$.

Com relação ao teor de cinzas de $2,47 \%$, resultados similares foram descritos por LOURENÇO (1999) $(1,55$ a 3,13\%) e SOUSA et al. (2002) (1,67 a 2,52\%). Entretanto, TORO \& SOUSA (2002), referiram teor médio menor $(2,08 \%)$ e GOUVEIA \& DIAS (2004) e FIGUEIREDO (2006) encontraram valores mais elevados, respectivamente, de $3,46 \%$ e entre 3,95 a 3,99\%.

LOURENÇO (1999), GOUVEIA \& DIAS (2004) e FIGUEIREDO (2006) atribuíram o elevado teor de cinzas, no Requeijão Marajoara, às elevadas proporções de cloreto de sódio $(\mathrm{NaCl})$ adicionadas à massa, uma vez que nem sempre se incorpora a quantidade de $1,5 \%$ de $\mathrm{NaCl}$ recomendada por $\mathrm{HUHN}$ et al. (1991). A variação (CV de 19\%) nos teores de cinzas, pode estar relacionada à falta de padronização de $\mathrm{NaCl}$ adicionada à massa durante o processo de fabricação.

Os resultados referentes às análises de parâmetros físico-químicos referentes ao queijo tipo Minas Frescal encontram-se na tabela 2. O valor médio de $\mathrm{pH}$ nas amostras estudadas foi de 6,26, semelhante aos relatados por YUNES \& BENEDET (2000) e por MARCATTI et al. (2009), que encontraram, respectivamente, $\mathrm{pH}$ de 6,49 e de 6,38 a 6,71. Entretanto, maior que o $\mathrm{pH}$ de 5,4 a 5,7 encontrado por VAN NIEUWENHOVE et al. (2007a; 2007b), no mesmo tipo de queijo produzido com leite de búfala, e por INAYAT et al. (2007) que acharam pH 5,47 em queijo de consistência mole, também produzido com leite bubalino. 
Tabela 2 - Composição físico-química do queijo tipo Minas Frescal elaborado com leite de búfalas, no município de Moju, Pará. Belém, 2011.

\begin{tabular}{llcc}
\hline & & & \\
& Marâmetros avaliados $\pm \sigma$ & Máximo & Mínimo \\
\hline Gordura no Extrato Seco (\%) & $62,95 \pm 4,38$ & 71,45 & 54,85 \\
Umidade (\%) & $60,99 \pm 2,58$ & 6,95 & 56,38 \\
Gordura (\%) & $25,09 \pm 1,68$ & 65,74 & 21,83 \\
Proteína (\%) & $11,08 \pm 1,65$ & 28,17 & 9,17 \\
Cinzas (\%) & $2,09 \pm 0,32$ & 14,3 & 1,44 \\
pH & $6,26 \pm 0,69$ & 2,93 & 14,89 \\
Acidez Titulável (\%) & $0,15 \pm 0,14$ & 6,86 & 15,31 \\
& & 0,49 & 11,02 \\
\hline
\end{tabular}

CV - Coeficiente de variação.

$\mathrm{O}$ pH no queijo Minas Frescal, apesar do valor médio encontrar-se dentro de parâmetros referidos em outros estudos, foi variável $(\mathrm{CV}=$ $11,02 \%$ ), o que pode ser atribuído ao processo de coagulação que ocorre de forma espontânea, segundo referiram HÜHN et al. (1986) e LOURENÇO (1999).

A acidez titulável de $0,15 \%$ de ácido lático mostrou-se semelhante àquela obtida por YUNES \& BENEDET (2000) de 0,13\%, para o mesmo tipo de queijo, e menor do que a acidez de $0,45 \%$ em ácido lático, encontrada por INAYAT et al. (2007) em amostras de queijo de massa mole, produzido com leite de búfala.

Ao comparar a acidez do Minas Frescal produzido com leite bubalino com o de bovino, verificou-se que ela se encontra entre as concentrações de 0,09 a $0,45 \%$ de ácido lático, relatadas por vários pesquisadores (COSTA et al., 2010; MACHADO et al., 2004; ROSA, 2004; ZARBIELLI et al., 2004; FRITZEN-FREIRE et al., 2010).

Neste experimento, o teor de umidade, de $60,99 \%$ foi maior que os encontrados por YUNES \& BENEDET (2000) e por MORAES et al. (2006), respectivamente, 58,77 e $55 \%$, também no Minas Frescal, produzido com leite bubalino, demonstrando a falta de padronização na elaboração desse tipo de queijo.

Comparando o Minas Frescal elaborado com leite de búfala com o produzido com leite bovino, observou-se similaridade com os percentuais de 36,4 a $61,67 \%$ referido por SILVA (2008) e de $62,3 \%$ encontrado por COSTA et al. (2010).

Considerando a inexistência de padrões específicos para os derivados lácteos bubalinos, o teor de umidade encontrou-se em conformidade com a Instrução Normativa no4 (BRASIL, 2004), recomendada para esse tipo de queijo produzido com leite bovino.

A acidez de $0,15 \%$ e a umidade de $60,99 \%$ foram semelhantes a resultados obtidos, nesse mesmo tipo de queijo produzido com leite bubalino, por outros pesquisadores, considerando que LOURENÇO NETO (1998) referiu que elevados teores de umidade e lactose no queijo Minas Frescal facilitam a produção de ácido láctico, associado à falta de critérios para elaboração desse tipo de queijo a partir do leite bubalino.

O teor de gordura de $25,09 \%$ foi acima dos $21,40 \%$ referidos por YUNES \& BENEDET (2000) e dos 18,3 a $21,2 \%$ relatados por VAN NIEUWENHOVE (2007a; 2007b). Entretanto, abaixo dos $26,22 \%$ deparados por MORAES et al. (2006) no mesmo tipo de queijo também elaborado com leite de búfala.

O percentual de GES, de $62,95 \%$ foi superior aos encontrados por YUNES \& BENEDET (2000) e por MORAES et al. (2006), respectivamente, 53,05 e $45 \%$ e ainda ao estabelecido na Instrução Normativa no4 (BRASIL, 2004), que prevê a GES no queijo tipo Minas Frescal, produzido com leite de vaca, em torno de 25 a $44,9 \%$.

Os elevados teores de gordura e GES encontrados e comparados a outros referidos na literatura, no Minas Frescal elaborado com leite de búfala, podem estar relacionados aos teores de gordura nesse leite, cuja composição varia em função da região, estação do ano, nutrição e do efeito do animal (raça, idade, estádio de lactação), conforme relatos de AMARAL et al. (2005) e ainda à falta de padrão utilizado na fabricação do queijo, corroborando com relatos de PINTO, GERMANO \& GERMANO (1996), sobre a necessidade de padronização das técnicas empregadas nos estabelecimentos industriais.

A concentração de $11,06 \%$ de proteína foi menor que as observadas por YUNES \& BENEDET (2000) $(12,68 \%)$, entretanto, semelhante ao teor de $11,5 \%$ encontrado por VAN NIENWENHOVE (2007a; 2007b) ao analisarem o mesmo tipo de queijo produzido com leite de búfalas. 
$\mathrm{Na}$ avaliação do teor de proteína, deve-se levar em consideração que o elevado conteúdo de umidade do queijo Minas Frescal, e também a concentração de gordura mais elevada no queijo analisado neste experimento, reduz a proporcionalidade do conteúdo de proteína.

O teor de cinzas de 2,09\% foi menor do que o verificado por YUNES \& BENEDET (2000) de $3,13 \%$ e maior que os $0,14 \%$ observados por MORAES et al. (2006) no queijo Minas Frescal, elaborado com leite bubalino.

Os resultados das análises físico-químicas do queijo Minas Frescal, neste experimento, estão em conformidade com os dados relatados por SALOTTI et al. (2006), SILVA (2008) e SILVA et al. (2009), de que o alto teor de umidade e o excesso de manipulação podem influenciar e dificultar a padronização da elaboração, ocasionando constantemente queijos em não conformidade com os padrões descritos nas legislações pertinentes.

\section{CONCLUSÃO}

De acordo com os resultados encontrados, pode-se concluir que os resultados encontrados assemelham-se, em grande parte, aos citados na literatura e, considerando a legislação pertinente a queijos semelhantes produzidos com leite bovino, o "Requeijão Marajoara" pode ser classificado como queijo gordo, de média umidade e de massa semidura, enquanto que o Minas Frescal, classificado como queijo extragordo e de muito alta umidade.

A falta de padronização da composição e das características físico-químicas dos queijos Minas Frescal e Requeijão Marajoara, elaborados a partir do leite de búfalas, caracterizaram uma variabilidade no processamento dos queijos, sendo necessária a aplicação de tecnologias e/ou padrões específicos, principalmente em estabelecimentos industriais de menor porte, como os pesquisados neste trabalho.

\section{REFERÊNCIAS}

AMARAL, F.R. et al. Qualidade do leite de búfalas: composição. Revista Brasileira de Reprodução Animal, v.29, n.2, p.106-110, 2005 .

BENDELAK, M.R. Processo produtivo e sugestão de implantação do sistema de análise de perigos e pontos críticos de controle na produção do queijo Marajoara tipo creme. 7o Prêmio Food Design em HACCP, 2005. Acesso em: 20 out. 2008. Online. Disponível em: <http://www.fooddesign.com.br/arquivos/ academia/7\%20Premio\%20Food\%20Design \%20>.

BENDELAK, M.R. Processo produtivo, características físicoquímicas e microbiológicas de implantação do sistema de análise de perigos e pontos críticos de controle na produção do queijo Marajoara tipo creme. 2004. 73f. Dissertação (Mestrado em Ciência Animal) - Universidade Federal do Pará, Universidade Rural da Amazônia, Empresa Brasileira de Pesquisa Agropecuária, Museu Paraense Emílio Goeldi, Belém, PA.

BRASIL. Ministério da Agricultura, Pecuária e Abastecimento. Secretaria de Defesa Agropecuária. Instrução Normativa $\mathrm{n}^{\mathrm{o}}$ 68 de 12 de dezembro de 2006. Métodos Analíticos Oficiais Físico-Químicos, para Controle de Leite e Produtos Lácteos, em conformidade com o anexo desta Instrução Normativa, determinando que sejam utilizados nos Laboratórios Nacionais Agropecuários. Diário da República Federativa do Brasil, p.8, 14 dez. 2006. Seção 1.

Ministério da Agricultura, Pecuária e Abastecimento. Secretaria de Defesa Agropecuária. Instrução Normativa no 04 de 01 de março de 2004. Regulamento Técnico para Fixação de Identidade e Qualidade em Queijo Minas Frescal - Alteração na "Classificação". Diário da República Federativa do Brasil, p.12, 2004.

Ministério da Agricultura, Pecuária e Abastecimento. Secretaria Nacional de Defesa Agropecuária. Regulamentos Técnicos de Identidade e Qualidade de Leite e Produtos Lácteos. Portaria no 352 de 1997. Regulamento Técnico de Identidade e Qualidade de Queijo Minas Frescal. Diário da República Federativa do Brasil, seção 01, p.76-78, 1997a.

Ministério da Agricultura, Pecuária e Abastecimento. Secretaria de Defesa Agropecuária. Departamento de Inspeção de Produtos de Origem Animal. Regulamentos Técnicos de Identidade e Qualidade de Leite e Produtos Lácteos. Portaria no 359. Regulamento técnico para fixação de identidade e qualidade do requeijão cremoso ou requesón. Brasília, DF, 1997 b.

Ministério da Agricultura, Pecuária e Abastecimento. Coordenação de Informação Documental Agrícola. Secretária de Documental Agrícola. Secretaria do Desenvolvimento Rural do Ministério da Agricultura e do Abastecimento e da Reforma Agrária. Regulamentos Técnicos de Identidade e Qualidade de Leite e Produtos Lácteos. Portaria no 146. Brasília, DF, 1996.

COSTA, M.P. et al. Avaliação da aceitação sensorial e do rendimento de fabricação de queijos minas frescal produzidos com leite de cabra e de vaca. In: CONGRESSO DE LATICÍNIOS, 27.; EXPOMAC, 38.; EXPOLAC, 37.; CONCURSO NACIONAL DE PRODUTOS LÁCTEOS, 37.; CONGRESSO INTERNACIONAL DO LEITE, EMPRESA AGROPECUÁRIA DE MINAS GERAIS (EPAMIG) 8, 2010, Juiz de Fora, Minas Gerais. Acesso em: 2 out. 2010. Online. Disponível em: <http://www.cnlepamig.com. br/anais/img/trabalhos_cnl/poster/005.pdf $>$.

CUNHA NETO, O.C. Avaliação do iogurte natural produzido com leite de búfala contendo diferentes níveis de gordura. 2003. 71f. Dissertação (Mestrado em Zootecnia) - Faculdade de Zootecnia e Engenharia de Alimentos, Universidade de São Paulo, Pirassununga, SP.

FIGUEIREDO, E.L. Elaboração e caracterização do “Queijo Marajó”, tipo creme, de leite de búfala, visando sua padronização. 2006. 104f. Dissertação (Mestrado em Ciência Animal) - Universidade Federal do Pará, Belém, PA

FRITZEN-FREIRE, C.B. et al. The effect of direct acidification on the microbiological, physicochemical and sensory properties of 
probiotic Minas Frescal cheese. International Journal of Dairy Technology, v.63, n.4, p.561-568, 2010

GOUVEIA, C.A.L.; DIAS, J.D.C. Caracterização do Queijo do Marajó e levantamento do pessoal envolvido no processo para orientação e inserção social. 2004. 69f. Monografia (Conclusão de Curso em Tecnologia Agroindustrial) - Universidade do Estado do Pará, Belém, PA.

HÜHN, S. et al. Características, peculiaridades e tecnologia do leite de búfala. Belém: Embrapa- CPATU, 1991. 51p. (Embrapa. Documentos, 57).

HÜHN, S. et al. Aproveitamento do leite de búfala em produtos derivados. In: SIMPÓSIO DO TRÓPICO ÚMIDO, 1984, Belém, Pa. Anais... Belém: EMBRAPA/CPATU, 1986. V.5, p.265-269. (Documentos, 36).

HÜHN, S. et al. Estudo comparativo da composição química de leite de zebuínos e bubalinos. Belém: EMBRAPA - CPATU, 1982. 15p. (Documento, 36)

INAYAT, S. et al. Study on the production and quality improvement of soft unripened cheese made from buffalo milk as compared with camel Milk. Italian Journal of Animal Science, v.6, suppl.2, p.1115-1119, 2007.

LOURENÇO, L.H.F. et al. Análise microbiológica do requeijão Marajoara elaborado no norte do Brasil. Revista Higiene Alimentar, v.16, n.96, p.55-59, 2002.

LOURENÇO, L.H.F. Análise da composição química, microbiológica, sensorial e dos aromas do requeijão Marajoara. 1999. 127f. Tese (Doutorado em Ciências Biológicas) Universidade Federal do Pará; Museu Paraense Emílio Goueldi; Empresa Brasileira de Pesquisa Agropecuária. Belém, PA.

LOURENÇO-NETO, J.P.M. O uso de culturas láticas na fabricação de Minas frescal como alternativa de melhoria de qualidade. In: SEMINÁRIO INTERNACIONAL "QUEIJOS FRESCOS”, 1998, Atibaia, SP. Anais... Atibaia,1998. p. 59-75.

MACHADO, E.C. et al. Características físico-química e sensoriais do queijo Minas artesanal produzido na região do Serro, Minas Gerais. Ciência e Tecnologia de Alimentos, v.24, n.4, p.516-521, 2004.

MARCATTI, B. et al. Minas-type fresh cheese developed from buffalo milk with addition of $\boldsymbol{L}$. Acidophilus. Scientia Agricola, v.66, n.4, p.481-485, 2009.

MORAES, M.C. et al. Caracterização do queijo minas Frescal e da matéria-prima elaborado a partir do leite de búfala. In: CONGRESSO BRASILEIRO DE QUÍMICA, 46., 2006, Salvador, BA. Anais... Salvador: Associação Brasileira de Química. Química Analítica, 2006. Acesso em: 12 ago. 2008. Online. Disponível em: <http://www.abq.org.br/cbq/2006/trabalhos2006/4/854-10344-T1.htm>.

PINTO, P.S.A. et al. Queijo Minas: problema emergente de Saúde Pública. Revista Higiene Alimentar, v.10, p.22-27, 1996.

ROSA, V.P. Efeitos da atmosfera modificada e da irradiação sobre as características microbiológicas, físico-químicas e sensoriais do queijo Minas Frescal. 2004. 141f. Dissertação (Mestrado em Ciência e Tecnologia de Alimentos) - Escola Superior de Agricultura Luiz de Queiroz, Universidade de São Paulo, SP.
SALOTTI, B.M. et al. Qualidade microbiológica de queijo Minas Frescal comercializado no Município de Jaboticabal, SP, Brasil. Arquivo do Instituto de Biologia, v.73, n.2, p.171-175, 2006.

SAS (SAS INSTITUTE). SAS/STAT ${ }^{\circledR}$ user's guide, version 6. 4.ed. Carry, NC, n.27, p.161-168, 1997.

SILVA, C.A.O. et al. Monitoramento da qualidade de queijo Minas Frescal, Mussarela e requeijão cremoso comercializados em Minas Gerais. In: XVI ENCONTRO NACIONAL DE ANALISTA DE ALIMENTOS, 16; CONGRESSO LATINO-AMERICANO DE ANALISTAS DE ALIMENTOS, 2, 2009, Belo Horizonte, MG. Anais... Belo Horizonte, 2009.

SILVA, T.V. Caracterização físico-química de queijos tipo minas Frescal produzidos por pequenos produtores do município de Guarapuava e região. In: SALÃO DE EXTENSÃO E CULTURA, 2008, Unicentro, Guarapuava/Irati, PR. Anais... Disponível em: $<$ http://www.unicentro.br/proec/publicacoes/salao2008/artigos/ Tatiana\%20Vanessa\%20Silva.pdf.>. Acesso em: 10 dez. 2010.

SILVA, V.R., OLIVEIRA, V.L. O Queijo do Marajó tipo "creme" derivado do leite de búfala: uma alternativa para o desenvolvimento sustentável do agronegócio no Município de Soure. 2003. 70f. Monografia (Especialização em Empreendedorismo Rural e Desenvolvimento Sustentável) Universidade do Estado do Pará, Belém, PA.

SOUSA, C. et al. Avaliação microbiológica e físico-química de doce de leite e requeijão produzidos com leite de búfala na Ilha do Marajó-PA. Boletim do Centro de Pesquisa e Processamento de Alimentos, v.20, n.2, p.191-202, 2002.

TORO, M.J.U; SOUSA, C.L. Microbiologic and phisicalchemical characteristics of cheese "Marajoara" sold in Belém, Pará State, Brazil. In: BUFFALO SYMPOSIUM OF AMÉRICAS, 2002, Belém, PA. Anais... Belém: APCB: FCAP editora, 2002. p.591-593.

VAN NIEUWENHOVE, C.P. et al. Chemical composition and fatty acid content of buffalo cheese from Northwest Argentina: effect on lipid composition of mice tissues. Journal of Food Lipids, v.14, p.232-243, 2007a.

VAN NIEUWENHOVE, C.P. et al. Influence of bacteria used as adjunct culture and sunflower oil addition on conjugated linoleic acid content in buffalo cheese. Food Research International, v. 40, p. $559-564,2007 b$.

VERRUMA-BERNARDI, M.R. et al. Elaboração do queijo mozarela de leite de búfala pelos métodos tradicional e da acidificação direta. Ciência e Tecnologia de Alimento, v.20, p.138-144, 2000.

VIEIRA, L.C. et al. Produção de requeijão Marajoara de leite de búfala. In: ZOOTEC'2005 Campo Grande, MS. Anais... Campo Grande, MS : ABZ: UEMS: UFMS: CPAP: MAPA, 2005. Zootec 2005. p. 1-4

YUNES, V.M.; BENEDET, H.D. Desenvolvimento experimental de queijo fresco de leite da espécie bubalina. Ciência e Tecnologia de Alimentos, v.20, n.3, p.285-290, 2000.

ZARBIELLI, M. et al. Formulação e caracterização físico-química e sensorial de queijo minas light enriquecido com fonte de ferro. Brazilian Journal of Food and Nutrition - Alimentos e Nutrição, v.15, n.3, p.251-257, 2004. 